\title{
Chemism of the run-off wastewater from urbanized areas based on the Kielce City example
}

\author{
A. Rabajczyk ${ }^{1}$, Ł. Bąk ${ }^{2}$ and J. Górski ${ }^{2}$ \\ ${ }^{1}$ Department of Environmental Protection and Modelling, The Jan Kochanowski University of Humanities and Sciences \\ in Kielce, ul. Świętokrzyska 15G, 25-406 Kielce, e-mail: chromium@tlen.pl, tel. +48 04134964 35, fax +48 04134964 \\ 18 \\ ${ }^{2}$ The Kielce University of Technology, Chair of Geotechnics and Water Engineering, 25-314 Kielce, Al. Tysiąclecia \\ Państwa Polskiego 7, Building A, 1.Bak@tu.kielce.pl
}

\begin{abstract}
The study was conducted at the collector of run-off wastewater (Si9), located in Kielce. Silnica River is a small river cutting through the city of Kielce from the North to the South-West. It has its source in Masłowskie Range at a height of $360 \mathrm{~m}$ a.s.l. and it flows into Bobrza River. It is ranked among mountain rivers at a $6.4 \%$ gradient. Its river-bed bas belonged to Kielecki Protected Landscape Area since 2006. Next to Szydłowek estate the artificial water body was build - Kielecki Bay. Beneath Kielecki Bay, Silnica River flows in regulated river-bed. Because of no separated storm water drainage, the rainwater washes away pollutants among others from industrial plants, houses, pavements, and streets into Silnica River. The wastewater treatment plant is located at the mouth of the Silnica River. It receives rainwater and snowmelt from the central - eastern part of the city with an area of 62 ha. The primary channel has a length of $1569 \mathrm{~m}$ and its diameter varies from $600 \mathrm{~mm}$ to $1250 \mathrm{~mm}$. Is attached to the side of seventeen channels (with diameters from $300 \mathrm{~mm}$ to $1000 \mathrm{~mm}$ ). The collector wells are 32 inspection and connection, and 24 entries. The side channels are located 119 wells and 82 outlets. The total length of the sewerage system is equal to $5583 \mathrm{~m}$. The decrease of the collector changes to individual sections from $0.04 \%$ to $3.9 \%$, and decreases in side channels to reach $2.61 \%$. On average, one groove receives water from the surface of 0.585 ha. Ordinate the highest point in the catchment area is $271.20 \mathrm{~m}, 260.0 \mathrm{~m}$ above sea level the lowest, the average decrease in surface area is equal to $0.71 \%$. Within the basin was isolated six types of surface runoff: roofs $(14.3 \%)$, walks $(8.4 \%)$, roads $(17.7 \%)$, parking $(11.2 \%)$, green $(47.2 \%)$ and pitch school $(1.3 \%)$. Generally, paved areas with a high coefficient of runoff represent $52.83 \%$ of the total catchment area, which shows the typical urban character. The run-off wastewater is collected from the roofs by gutters incorporated directly into storm channels ( $72.5 \%$ of all roofs), with roads and streets on a typical street drains with cast iron grate. A qualitative and quantitative study of runoff wastewater was conducted between February 2011 and October 2011. The study covered metals of Fe, Cd, $\mathrm{Cr}, \mathrm{Al}$ and $\mathrm{Mn}$, ions of $\mathrm{Ca}^{2+}, \mathrm{Mg}^{2+}, \mathrm{Na}^{+}, \mathrm{K}^{+}, \mathrm{NH}_{4}{ }^{+}, \mathrm{Cl}^{-}, \mathrm{F}^{-}, \mathrm{NO}_{3}{ }^{-}, \mathrm{SO}_{4}{ }^{2-}$ and $\mathrm{PO}_{4}{ }^{3-}$ as well as the distribution of rainfall intensity, the $\mathrm{pH}$ and conductivity. The levels of these selected heavy metals were determined using $\mathrm{F}$ AAS and/or ICP-MS-TOF (GBC), but the levels of selected ions were identified by means of ion chromatography (Dionex ICS-3000).
\end{abstract}

Key words: run-off wastewater, metals, inorganic ions, urban area 